ORIGINAL ARTICLE

\title{
Rehospitalisation after birth hospitalisation: patterns among infants of all gestations
}

\author{
G J Escobar, J D Greene, P Hulac, E Kincannon, K Bischoff, M N Gardner, M A Armstrong, \\ E K France
}

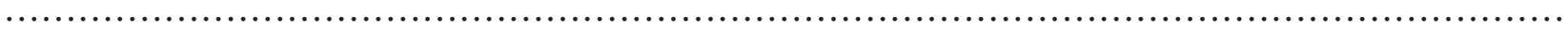

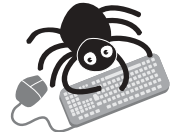

Supplementary material is available on the Archives of Disease in Childhood website (www.archdischild.com/ supplemental)

See end of article for authors' affiliations

aus

Correspondence to: $\operatorname{Dr} G J$ Escobar, Kaiser Permanente Medical Care Program, Division of Research, Perinatal Research Unit, 2000 Broadway, 2nd floor, Oakland, CA 94612, USA; gabriel.escobar@kp. org

Accepted 7 July 2004

Aim: To analyse rehospitalisation of newborns of all gestations.

Methods: A total of 33276 surviving infants of all gestations born between 1 October 1998 and 31 March 2000 at seven Kaiser Permanente Medical Care Program (KPMCP) delivery services were studied retrospectively.

Results: Rehospitalisation rates within two weeks after nursery discharge ranged from $1.0 \%$ to $3.7 \%$. The most common reason for rehospitalisation was jaundice. Among babies $\geqslant 34$ weeks, the most important factor with respect to rehospitalisation was use of home phototherapy. Among babies who were not rehospitalised for jaundice, African-American race (adjusted odds ratio $(A O R)=0.56$ ), and having a scheduled outpatient visit (AOR $=0.73$ ) or a home visit $(A O R=0.59$ ) within 72 hours after discharge were protective. Factors associated with increased risk were: being small for gestational age (AOR = 1.83), gestational age of 34-36 weeks without admission to the neonatal intensive care unit (AOR = 1.65), Score for Neonatal Acute Physiology, version II, $\geqslant 10$ ( $A O R=1.95)$, male gender ( $A O R=1.24$ ), having both a home as well as a clinic visit within 72 hours after discharge (AOR =1.84), and birth facility (range of $A O R s=1.52-2.36)$. Asian race was associated with rehospitalisation $(A O R=1.49$ ) when all hospitalisations were considered, but this association did not persist if hospitalisations for jaundice were excluded. Conclusions: In this insured population with access to integrated care, rehospitalisation rates for jaundice were strongly affected by availability of home phototherapy and by follow up. For other causes, moderate prematurity and follow up visits played a large role, but variation between centres persisted even after controlling for multiple factors. Future research should include development of better process measures for evaluation of follow up strategies.

R ecently, rehospitalisation of healthy term newborns has received scientific and media attention..$^{1-9}$ Less research has been done on short term rehospitalisation of other newborns. ${ }^{10} 11$ In 1999 we reported on rehospitalisations among newborns admitted to the neonatal intensive care unit (NICU). ${ }^{12}$ We found that the highest rehospitalisation rate occurred among newborns 33-36 weeks gestation that had a length of stay (LOS) of less than four days. We also found considerable inter-facility variation in rehospitalisation rates.

The purpose of this study was to take a more comprehensive look at neonatal rehospitalisation. Unlike our previous study, we included all surviving infants and paid greater attention to inter-facility variation. We sought to identify patterns that could be useful to practitioners making newborn discharge and short term follow up decisions.

\section{METHODS}

Study setting

Our study setting consisted of seven Kaiser Permanente Medical Care Program (KPMCP) delivery centres, a managed care organisation resembling the British National Health Service $^{13}$ in some respects (for example, physicians are salaried, and care is provided on a capitated basis). At two of these sites, alliance facilities, KPMCP providers share the clinical facilities with fee-for-service providers. This study does not include non-KPMCP patients. Board certified neonatologists staff all seven KPMCP newborn services. Infants requiring some forms of specialised care (for example, extracorporeal membrane oxygenation) are transported to university centres but often return to KPMCP facilities before discharge home. High risk newborns discharged from the seven study sites receive follow up services, such as home visits, from the KPMCP and agencies in California and Colorado.

Within the KPMCP, admission to the NICU is always left to the treating physician's discretion, except with respect to premature and low birth weight infants. For these infants, mandatory admission to the NICU policies exist but these vary by facility (that is, one facility may mandate automatic admission for birth weight $<2500 \mathrm{~g}$ while another employs a $<2000 \mathrm{~g}$ cut-off). Discharge decisions, decisions to initiate specific treatments (for example, for jaundice), and policies for which baby gets a follow up home visit (as opposed to a clinic visit) are generally based on facility specific policies. However, none of these facilities have mandatory chronological age or attained weight criteria for discharge. Since individual KPMCP facilities have fairly broad budgetary autonomy, individual facilities may differ on how they allocate resources (for example, whether or not to employ home phototherapy, whether or not to invest in follow up clinics as opposed to home health visits).

The KPMCP Institutional Review Board for the Protection of Human Subjects approved this study.

\section{Study population}

The study included all live births between 1 October 1998 and 31 March 2000. The methods employed to link data sources

Abbreviations: AOR, adjusted odds ratio; KPMCP, Kaiser Permanente Medical Care Program; LOS, length of stay; NICU, neonatal intensive care unit 
have been published elsewhere. ${ }^{12}{ }^{14-19}$ We used the Kaiser Permanente Neonatal Minimum Data Set (NMDS) database ${ }^{20}$ to develop a retrospective cohort of NICU admissions. Inclusion criteria consisted of: (1) NICU admission with a date of birth in the study period; (2) birth at one of the seven facilities; and (3) surviving to discharge. We did not include babies transported into these seven NICUs (outborn babies).

Babies not admitted to the NICU were identified from KPMCP hospitalisation databases. Variables such as gestational age were obtained from the NMDS database ${ }^{20}$ or from other KPMCP databases. We calculated LOS using time of birth and time of first discharge home (if transport occurred, it includes time spent in multiple facilities). Post-menstrual age at discharge was calculated by adding hospital LOS to gestational age. KPMCP databases tracking provision of home nursing visits and home phototherapy were also scanned. We did not have access to data for follow up services provided by California or Colorado agencies.

KPMCP information systems use a common medical record number, which permits easy linkage of hospitalisation, rehospitalisation, clinical, and laboratory data for a given member, as well as linkage of a maternal to a neonatal record. Babies born to KPMCP women members are automatically covered for the first month of life, which permits attaining very high follow up rates. We determined which babies completed their automatic membership month during the study time period, then scanned the length of enrolment database to identify which of these babies did not continue KPMCP membership. We also searched KPMCP outpatient, inpatient, and out-of-plan utilisation databases to determine who did not have utilisation during the 21 days following NICU discharge, and would therefore be lost to follow up. These babies were not included in multivariate analyses.

\section{Newborn groups, diagnoses, and severity of illness}

Based on previous studies, ${ }^{12}{ }^{15}{ }^{21-23}$ we suspected that some infants were at higher risk of rehospitalisation, and that five diagnostic categories (jaundice only; jaundice with other diagnoses; feeding difficulties; evaluation for bacterial infection ("rule out sepsis"); and confirmed urinary tract infections) accounted for most rehospitalisations. We divided survivors into three groups: very premature ( $<34$ weeks) infants, who are automatically admitted to the NICU; moderately premature infants (34-36.9 weeks); and term infants ( $\geqslant 37$ weeks). Among babies $\geqslant 34$ weeks, we examined three admission types: normal newborn care; brief $(<24$ hours) admission to the NICU; and formal NICU admission ( $\geqslant 24$ hours in the NICU).

We grouped International Classification of Diseases ${ }^{24}$ rehospitalisation discharge diagnoses as follows:

- Jaundice: 773.0, 773.1, 773.2, 773.4, 774.0, 774.1, 774.2, $774.30,774.31,774.39,774.6,774.7,782.4$ and/or procedure codes 99.83 and/or 99.01

- Feeding difficulties: diagnoses beginning with 276; 775.5, 779.3, 785.50, and 785.59

- "Rule out sepsis": V29.0, V29.1, 079.9, 778.4, and 780.6

- Confirmed urinary tract infection: diagnoses beginning with 590 and 599.0.

When more than one category applied, we counted the child as belonging to each category. A rehospitalisation where any of the following occurred was considered "severe/prolonged": (1) LOS exceeded seven days; (2) assisted ventilation; (3) inter-hospital transport; and/or (4) death.

All newborns who remained in the NICU for $\geqslant 24$ hours were assigned a 12 hour Score for Neonatal Acute Physiology, version II (SNAP-II).${ }^{25}$ The SNAP-II score, which is similar in some ways to the CRIB, ${ }^{26}$ assigns points based on physiological derangements in the first 12 hours in the NICU as measured by the following variables: (1) the lowest mean arterial blood pressure, temperature, ratio of arterial oxygen tension to fraction of inspired oxygen, and $\mathrm{pH} ;(2)$ whether or not a newborn had seizures; and (3) urine output. Babies' SNAP scores can range between 0 and 115, although survival is unusual with scores $>50$. A general rule of thumb is that, above a score of 9, one SNAP-II point is roughly equivalent to a $0.3-0.6 \%$ mortality risk. For analytical purposes, newborns not assigned a SNAP-II (healthy newborns or newborns in the NICU for $<24$ hours) received scores of 0.

\section{Statistical methods}

Bivariate comparisons of potential predictors that were categorical to rehospitalisation were performed using the $\chi^{2}$ test or Fisher's exact test in the case of small cell sizes. Continuous variables were examined using Student's $t$ test if normally distributed and the Wilcoxon non-parametric test if not normally distributed.

Initial selection of variables for multivariate models was based on the results of bivariate comparisons, biological plausibility (for example, we included race because it is associated with differences in bilirubin levels ${ }^{27}$ ), and results of previous studies. ${ }^{12} 1518$ Centre was included in these models as a fixed effect. Variables were retained in the final model if they reached statistical significance or if the fact that they did not reach statistical significance was clinically significant.

The small number of centres in our study limited our ability to employ statistical techniques that specifically address the issue of clustering. ${ }^{28}$ Therefore, we used a simplified approach to explore centre level predictor effects (for example, monthly delivery volume). This consisted of eliminating the facility variable from the multivariate model, substituting the centre level predictor of interest for the facility variable, determining the adjusted odds ratio (AOR) and $95 \%$ confidence interval (95\% CI) for the predictor, and comparing the c-statistics of the resulting models to assess predictive ability. A c-statistic value near 0.5 indicates no discriminatory power, whereas a value of 1.0 indicates perfect discrimination..$^{29}$ The value of the c-statistic also equals the area under the receiver operating characteristic (ROC) curve. All statistical analyses employed SAS. ${ }^{30}$

\section{RESULTS}

During the study period, 33374 live births occurred at the study sites and 33276 (99.7\%) survived to discharge. A total of 3811 babies were admitted to the NICU and 3744 survived to discharge. An additional 31 deaths occurred among newborns never admitted to the NICU (newborn comfort care and delivery room deaths). We did not find significant inter-facility differences in in-hospital neonatal mortality rates. Of the 33276 survivors, $862(2.6 \%)$ were $<34$ weeks gestation, $2153(6.5 \%)$ were 34-36 weeks, and 30261 $(90.9 \%)$ were $37+$ weeks. Rehospitalisation rates varied by gestational age range: 26/862 (3.0\%) among babies $<34$ weeks, 94/2153(4.4\%) among babies 34-36 weeks, and $618 / 30261(2.0 \%)$ among babies $37+$ weeks. Table 1 provides data from individual facilities and shows the variation with respect to numbers and characteristics (for example, birth weight) of patients. Additional data on individual hospitals can be found in an appendix (see $A D C$ website).

The most common reason for rehospitalisation was jaundice, with $253 / 738$ (34.3\%) of the 738 rehospitalisations falling into the "jaundice only" category and an additional $129 / 738$ (17.5\%) having jaundice plus some other diagnosis. Among the infants in the "jaundice only" category, all but one were $\geqslant 34$ weeks gestation at birth. Other reasons were 


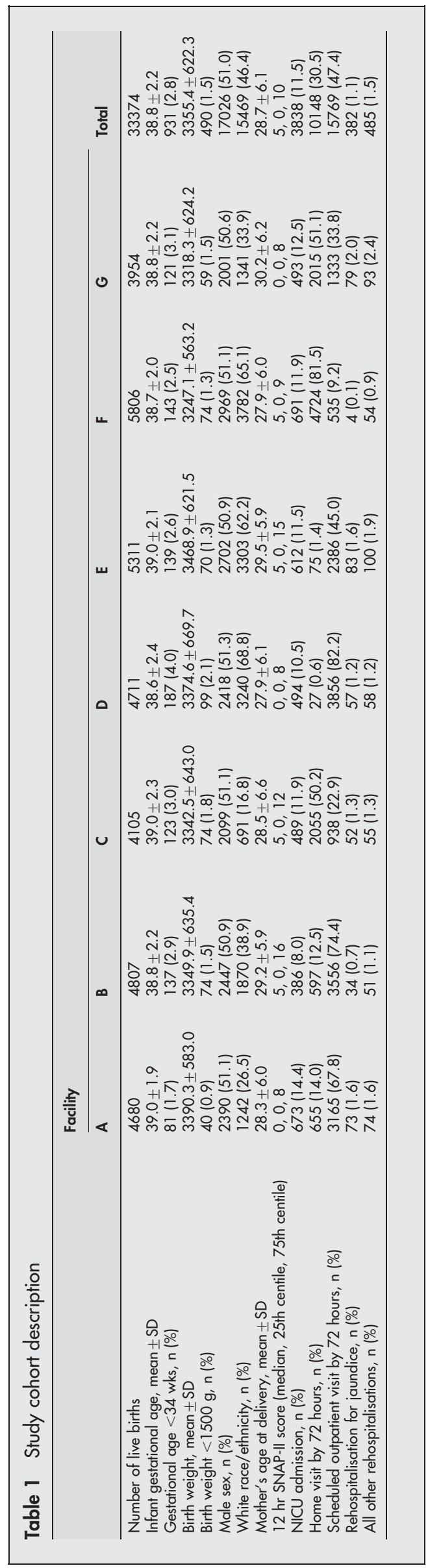

less common: feeding difficulties were present in $26.0 \%$ of the rehospitalisations, "rule out sepsis" in $11.1 \%$, severe or prolonged illness in $10.0 \%$, and miscellaneous reasons in $24.1 \%$. Many infants had more than one diagnosis. Among babies rehospitalised with "jaundice only", 84\% of the rehospitalisations occurred within 72 hours after discharge while among other rehospitalisations, $46 \%$ occurred within 72 hours.

Considerable variation in overall rehospitalisation rates and in rehospitalisation rates for specific conditions was present across facilities. The degree of variation with respect to phototherapy use was different if one also considered home phototherapy. For example, among babies 34-36.9 weeks gestation, the jaundice rehospitalisation rate ranged from $0.3 \%$ to $4.5 \%$, whereas the range of infants treated with phototherapy (occurring at home or in the hospital) was 2.2$5.9 \%$. Among babies $\geqslant 37$ weeks gestation, the jaundice rehospitalisation rate ranged from $0.0 \%$ to $1.2 \%$, whereas the range of infants treated with phototherapy was $0.7 \%$ to $1.3 \%$. Among babies $\geqslant 34$ weeks gestation at birth, the overall rehospitalisation rate for "jaundice only" at the five facilities that did not have ready access to home phototherapy was $1.0 \%$, whereas at the other two facilities this rate was $0.3 \%$. This difference was significant $(p<0.0001)$. The rate of treatment with phototherapy at the five facilities that did not have ready access to home phototherapy was $1.1 \%$, whereas at the two facilities with ready access this rate was $1.4 \%$ $(\mathrm{p}=0.0052)$.

\section{Multivariate analyses}

Table 2 shows our final multivariate logistic model for prediction of rehospitalisation for all causes. Asian infants were more likely to be rehospitalised (AOR $=1.49$ ), whereas African-American infants were at lower risk $(\mathrm{AOR}=0.61)$. Male infants were more likely to be rehospitalised than female infants ( $\mathrm{AOR}=1.28)$, as were infants who were small for gestational age $(\mathrm{AOR}=1.76)$ and those with a SNAP-II $\geqslant 10(\mathrm{AOR}=2.00)$. Infants born at 34-36 weeks gestation who were never in the NICU $(\mathrm{AOR}=3.10)$ were at higher risk. Having both a home visit as well as a scheduled outpatient visit within 72 hours was also associated with an increased risk $(\mathrm{AOR}=1.94)$. Having had a home health visit $(\mathrm{AOR}=0.66)$ or a scheduled outpatient visit $(\mathrm{AOR}=0.83)$ within 72 hours after discharge were associated with a decreased risk. Considerable inter-facility variation persisted in this model.

Table 3 shows our final multivariate model for prediction of rehospitalisation among all infants when infants in the "jaundice only" category were excluded. Results are similar to those of table 2, with the same predictors being statistically significant except for Asian race.

Table 4 compares the results of the model described in table 3 with those obtained when we substituted centre level predictors (for example, monthly delivery volume in units of 50 births/month) for facility terms. None of these models were superior to our original model (all had c statistics $<0.636)$. Centre characteristics associated with decreased rehospitalisation were availability of home phototherapy, being at an alliance facility, having an increased proportion of non-white births, having a higher monthly delivery volume, and having a higher mean SNAP-II. Centre characteristics associated with increased rehospitalisation rates were having a paediatric residency programme and having a higher NICU admission rate.

\section{DISCUSSION}

Moderately premature infants constitute more than $80 \%$ of all premature infants in the United States, ${ }^{31}$ but little is known about their outcomes. A growing body of literature 


\begin{tabular}{|c|c|c|}
\hline & AOR & $95 \% \mathrm{Cl}$ \\
\hline \multicolumn{3}{|l|}{ Maternal age } \\
\hline Age $<18$ years & 0.98 & 0.60 to 1.61 \\
\hline Age $18-34$ years & Ref & \\
\hline Age $35+$ years & 1.05 & 0.87 to 1.26 \\
\hline \multicolumn{3}{|l|}{ Infant sex } \\
\hline Male & 1.28 & 1.11 to 1.49 \\
\hline Female & Ref & \\
\hline \multicolumn{3}{|l|}{ Race } \\
\hline African-American & 0.61 & 0.43 to 0.86 \\
\hline Asian & 1.49 & 1.22 to 1.82 \\
\hline Hispanic & 1.10 & 0.90 to 1.35 \\
\hline Other & 1.20 & 0.88 to 1.62 \\
\hline White & Ref & \\
\hline \multicolumn{3}{|l|}{ Small for gestational age ( $<5$ th centile) } \\
\hline Yes & 1.76 & 1.07 to 2.91 \\
\hline No & Ref & \\
\hline \multicolumn{3}{|l|}{ Gestational age and NICU admission } \\
\hline Less than 34 weeks $†$ & 0.96 & 0.57 to 1.62 \\
\hline $34-36$ weeks, in NICU $\geqslant 24$ hours & 0.89 & 0.54 to 1.46 \\
\hline $34-36$ weeks, in NICU $<24$ hours & 1.31 & 0.41 to 4.21 \\
\hline 34-36 weeks, never in NICU & 3.10 & 2.38 to 4.02 \\
\hline $37+$ weeks, in NICU $\geqslant 24$ hours & 0.79 & 0.52 to 1.21 \\
\hline $37+$ weeks, in NICU $<24$ hours & 1.43 & 0.73 to 2.81 \\
\hline $37+$ weeks, never in NICU & Ref & \\
\hline \multicolumn{3}{|l|}{ Score for neonatal acute physiology (SNAP-II) } \\
\hline 0 & Ref & \\
\hline $1-9$ & 1.52 & 0.89 to 2.61 \\
\hline$\geqslant 10$ & 2.00 & 1.19 to 3.36 \\
\hline \multicolumn{3}{|l|}{ Facility of birth } \\
\hline A & 2.06 & 1.45 to 2.94 \\
\hline B & 1.16 & 0.79 to 1.70 \\
\hline $\mathrm{C}$ & 1.89 & 1.33 to 2.69 \\
\hline D & 1.92 & 1.33 to 2.77 \\
\hline $\mathrm{E}$ & 2.12 & 1.50 to 3.00 \\
\hline $\mathrm{F}$ & Ref & \\
\hline G & 3.05 & 2.21 to 4.22 \\
\hline \multicolumn{3}{|l|}{ Follow up status after birth hospitalisation discharge home } \\
\hline Scheduled outpatient visit only within 72 hours & 0.83 & 0.69 to 1.00 \\
\hline Home health visit only within 72 hours & 0.66 & 0.51 to 0.84 \\
\hline Scheduled outpatient and home visit within 72 hours & 1.94 & 1.32 to 2.84 \\
\hline No follow up within 72 hours & Ref & \\
\hline c statistic & 0.657 & \\
\hline Hosmer-Lemeshow $p$ value & 0.6447 & \\
\hline
\end{tabular}

suggests that these babies, who have received much less research attention than very low birth weight infants, deserve scrutiny. Moderately premature infants contribute significantly to overall neonatal mortality rates $^{21}$ and have been reported to have rates of long term morbidity (for example, cerebral palsy) that are intermediate between those of term and very premature infants. ${ }^{1522}{ }^{23}$ It seems likely that their overall contribution to childhood morbidity is significant. Our finding that moderately premature infants who are never admitted to the NICU experience increased rehospitalisation is important. One possible explanation is that clinicians may be making clinical judgments based on infants' birth weight rather than gestation. In a separate report, we have reported this concern with respect to neonatal jaundice. ${ }^{32}$

Despite the presence of an integrated system, significant variation exists in the use of home phototherapy and follow up visits. Several studies have shown that home phototherapy is safe, ${ }^{33-35}$ but our study is the first to show the impact of home phototherapy on a population basis. Not all paediatricians are comfortable with this technology. ${ }^{36}$ Poland has suggested that this reflects a general scepticism about the need to treat jaundice at all, ${ }^{37}$ a supposition supported by another of our studies. ${ }^{38}$ On the other hand, our data suggest that, at facilities employing home phototherapy, clinicians may have a lower threshold for initiating it than for rehospitalisation. If one wanted to assess the benefits of home phototherapy, it would be critical to address the issue of who needs phototherapy in the first place, a point raised by Plastino $^{39}$ and Newman and Maisels. ${ }^{40}$ Doing so should include better description of the context in which phototherapy is provided (that is, whether it is part of a broader case management system).$^{41}$

Although the KPMCP has compared home visits to clinic visits among term infants, ${ }^{42}{ }^{43}$ formal assessments of follow up strategies for premature or high risk infants (for example, term babies who experienced assisted ventilation) are absent from the literature. Our findings also highlight the need for better data about the content of home visits and outpatient follow up visits. In one set of patients - those who had both a home visit as well as a clinic visit-the reason for increased rehospitalisation is probably that the nurse conducting the home visit identified the baby as being at higher risk and referred the baby to the clinic, where the final decision to rehospitalise occurred. However, for the remaining patients, electronic data cannot support any inferences as to whether the effect of a given clinic or home visit was to prevent or detect the need for hospital care. While there are some guidelines for what should occur during the course of these visits, ${ }^{44}$ there are no guidelines for what sort of information should be captured about these visits. 


\begin{tabular}{|c|c|c|}
\hline & AOR & $95 \% \mathrm{Cl}$ \\
\hline \multicolumn{3}{|l|}{ Maternal age } \\
\hline Age $<18$ years & 1.04 & 0.58 to 1.87 \\
\hline Age $18-34$ years & Ref & \\
\hline Age $35+$ years & 1.10 & 0.88 to 1.37 \\
\hline \multicolumn{3}{|l|}{ Infant sex } \\
\hline $\begin{array}{l}\text { Male } \\
\text { Female }\end{array}$ & $\begin{array}{l}1.24 \\
\text { Ref }\end{array}$ & 1.04 to 1.49 \\
\hline \multicolumn{3}{|l|}{ Race } \\
\hline African-American & 0.56 & 0.37 to 0.85 \\
\hline Asian & 1.02 & 0.78 to 1.32 \\
\hline Hispanic & 0.98 & 0.77 to 1.25 \\
\hline Other & 1.08 & 0.75 to 1.56 \\
\hline White & Ref & \\
\hline \multicolumn{3}{|l|}{ Small for gestational age ( $<5$ th centile) } \\
\hline Yes & 1.83 & 1.04 to 3.25 \\
\hline No & Ref & \\
\hline \multicolumn{3}{|l|}{ Gestational age and NICU admission } \\
\hline$<34$ weeks & 1.30 & 0.74 to 2.28 \\
\hline $34-36$ weeks, in NICU $\geqslant 24$ hours & 0.85 & 0.47 to 1.54 \\
\hline $34-36$ weeks, in NICU $<24$ hours & 0.62 & 0.09 to 4.50 \\
\hline 34-36 weeks, never in NICU & 1.65 & 1.09 to 2.51 \\
\hline $37+$ weeks, in NICU $\geqslant 24$ hours & 1.08 & 0.69 to 1.70 \\
\hline $37+$ weeks, in NICU $<24$ hours & 1.16 & 0.48 to 2.84 \\
\hline $37+$ weeks, never in NICU & Ref & \\
\hline \multicolumn{3}{|l|}{ Score for neonatal acute physiology (SNAP-II) } \\
\hline 0 & Ref & \\
\hline $1-9$ & 1.50 & 0.83 to 2.70 \\
\hline$\geqslant 10$ & 1.95 & 1.12 to 3.41 \\
\hline \multicolumn{3}{|l|}{ Facility of birth } \\
\hline A & 1.52 & 1.02 to 2.27 \\
\hline B & 0.98 & 0.64 to 1.50 \\
\hline C & 1.34 & 0.90 to 2.01 \\
\hline D & 1.17 & 0.77 to 1.80 \\
\hline $\mathrm{E}$ & 1.57 & 1.07 to 2.31 \\
\hline $\mathrm{F}$ & Ref & \\
\hline G & 2.36 & 1.65 to 3.38 \\
\hline \multicolumn{3}{|l|}{ Follow up status after birth hospitalisation discharge home } \\
\hline Scheduled outpatient visit only within 72 hours & 0.73 & 0.58 to 0.92 \\
\hline Home health visit only within 72 hours & 0.59 & 0.45 to 0.79 \\
\hline Scheduled outpatient and home visit within 72 hours & 1.84 & 1.18 to 2.89 \\
\hline No follow up within 72 hours & Ref & \\
\hline c statistic & 0.636 & \\
\hline Hosmer-Lemeshow $p$ value & 0.9811 & \\
\hline
\end{tabular}

We also found that increased illness severity, as measured by the SNAP-II, was associated with an increased rehospitalisation risk. Although this makes intuitive clinical sense and is consistent with our previous study, ${ }^{12}$ this finding is important. SNAP-II was designed to predict mortality but seems to have similar properties to SNAP-I, which, in addition to being validated as a predictor for mortality, also predicts other outcomes, such as LOS. ${ }^{45}$ The SNAP-II is a simple score and can be assigned in less than five minutes. It may become useful for NICUs to employ it for clinical, not just research, purposes (for example, to help assign babies to different follow up programmes).

Table 4 Multiple multivariate models for rehospitalisation with facility terms replaced by centre level predictors

\begin{tabular}{|c|c|c|c|}
\hline Centre level predictor* & Categories† & $\begin{array}{l}\text { AOR }(95 \% \mathrm{CI}) \\
\text { for predictor }\end{array}$ & $\begin{array}{l}\text { c statistic for model } \\
\text { Reference: } 0.636 \ddagger\end{array}$ \\
\hline $\begin{array}{l}\text { Ready availability of home phototherapy } \\
\text { Paediatrics residency programme } \\
\text { Alliance facility } \\
\text { Overall facility home visit within } 72 \text { hours rate } \\
\text { Percent non-white (births) } \\
\text { Monthly delivery volume } \\
\text { Mean } 12 \text { hour SNAP-II score } \\
\text { Facility NICU admission rate } \\
\text { Facility brief ( }<24 \text { hours) NICU admission rate }\end{array}$ & $\begin{array}{l}\text { D } \\
\text { D } \\
\text { D } \\
10 \% \\
10 \% \\
50 \text { births/month } \\
2 \text { SNAP-II points } \\
2.5 \% \\
0.4 \%\end{array}$ & $\begin{array}{l}0.61(0.49 \text { to } 0.77) \\
1.52(1.23 \text { to } 1.87) \\
0.71(0.55 \text { to } 0.92) \\
1.00(0.96 \text { to } 1.04) \\
0.87(0.80 \text { to } 0.96) \\
0.77(0.66 \text { to } 0.89) \\
0.86(0.76 \text { to } 0.97) \\
1.23(1.08 \text { to } 1.39) \\
1.04(0.99 \text { to } 1.10)\end{array}$ & $\begin{array}{l}0.618 \\
0.622 \\
0.615 \\
0.609 \\
0.613 \\
0.618 \\
0.609 \\
0.616 \\
0.611\end{array}$ \\
\hline
\end{tabular}


We found that African-American infants are less likely, and Asian infants more likely, to be rehospitalised. Raised bilirubin levels are less common in African-American infants and more common in Asian infants in the KPMCP. ${ }^{17}{ }^{27}$ Also, in the United States, African-American mothers are less likely to breast feed, which has a strong effect on the second most common reason for rehospitalisation (feeding difficulties), a factor which $\mathrm{we}^{18}$ and others ${ }^{46}$ have described.

We cannot explain the increased likelihood of rehospitalisation in male infants. In one of our previous studies, ${ }^{17}{ }^{27}$ we reported an increased risk for severe $(\geqslant 25 \mathrm{mg} / \mathrm{dl})$ jaundice in male infants. However, in this study, the increased risk in male infants was not limited to rehospitalisation for jaundice.

We explored whether centre characteristics, such as patient volume, were associated with rehospitalisation rates. Our results in this area are tentative but could guide future cooperative studies. Phibbs et al have reported improved patient outcomes in NICUs with larger volumes, ${ }^{47}$ so it is conceivable that centres with more volume and/or experience with handling sicker infants (as evidenced by a facility's mean SNAP-II) might, over time, have developed better approaches to discharge management.

In conclusion, we have found that variation in short term neonatal jaundice rehospitalisation rates are strongly affected by the availability of home phototherapy and follow up care. Moderate prematurity and follow up visits largely contributed to the non-jaundice rehospitalisation rate, but variation between centres persisted even after controlling for multiple factors. Therefore, variation among newborn rehospitalisation rates cannot be explained completely by either biological or health services factors. Future research should include development of better process measures for evaluation of follow up strategies.

\section{ACKNOWLEDGEMENTS}

This project was supported by a grant from the Sidney Garfield Memorial Fund. Funding for the Neonatal Minimum Data Set Database in California was provided by the Kaiser Foundation Health Plan, Inc., and by The Permanente Medical Group, Inc. We wish to thank Ms Emily Breed and Ms Kimberley Harris for assistance with preparation of the manuscript. We also wish to thank Dr Andy Avins for reviewing the manuscript.

\section{Authors' affiliations \\ G J Escobar, J D Greene, M N Gardner, M A Armstrong, Kaiser} Permanente Medical Care Program, Division of Research, Perinatal Research Unit, 2000 Broadway, 2nd floor, Oakland, CA 94612, USA P Hulac, University of Colorado Health Sciences Center, Section of Neonatology, 4200 E. 9th Avenue, Denver, CO 80262, USA

E Kincannon, Department of Neonatology, Colorado Permanente Medical Group, Inc., 1375 East 20th Avenue, Denver, CO 80205, USA K Bischoff, Research and Development Department, Kaiser Permanente, 2550 S. Parker Road, Aurora, CO 80114 , USA

E K France, Department of Preventive Medicine, Kaiser Permanente, 10350 East Dakota Avenue, Denver, CO 80231, USA

Competing interests: none declared

Presented at a poster session at the May 2002 meeting of the Society for Pediatric Research

\section{REFERENCES}

1 Braveman P, Kessel W, Egerter S, et al. Early discharge and evidence-based practice. Good science and good judgment. JAMA 1997;278:334-6.

2 Congress of the United States of America. Newborns and Mothers Health Protection Act (P.L. 96-104), 1996.

3 Congress of the United States of America. Departments of Veterans Affairs and Housing and Urban Development, and Independent Agencies Appropriation Act 1997.

4 Gazmararian JA, Koplan JP. Length-of-stay after delivery: managed care versus fee-for-service. Health Aff (Millwood) 1996;15(4):74-80.

5 Kessel W, Kiely M, Nora A, et al. Early discharge: in the end, it is judgment. Pediatrics 1995;96(4 pt 1):739-42.
6 Soskolone EL, Schumacher R, Fyock C, et al. The effect of early discharge and other factors on readmission rates in newborns. Arch Pediatr Adolesc Med 1996; 150:373-9

7 Lee KS, Perlman M, Ballantyne M, et al. Association between duration of neonatal hospital stay and readmission rate. J Pediatr 1995;127:758-66.

8 Liu L, Clemens C, Shay D, et al. The safety of newborn early discharge. JAMA 1997; 278:293-8.

9 Edmonson MB, Stoddard JJ, Owens LM. Hospital readmission with feedingrelated problems after early postpartum discharge of normal newborns. JAMA 1997;278:299-303

10 Kotagal UR, Perlstein PH, Gamblian V, et al. Description and evaluation of a program for the early discharge of infants from a neonatal intensive care unit. J Pediatr 1995;127:285-90.

11 Gray JE, McCormick MC, Richardson DK, et al. Normal birth weight intensive care unit survivors: outcome assessment. Pediatrics 1996;97(6 pt 1):832-8.

12 Escobar GJ, Joffe SJ, Gardner MN, et al. Rehospitalization in the first two weeks after discharge from the neonatal intensive care unit. Pediatrics 1999; 104:1-9.

13 Feachem RG, Sekhri NK, White KL. Getting more for their dollar: a comparison of the NHS with California's Kaiser Permanente. BMJ 2002;324:135-41.

14 Selby JV. Linking automated databases for research in managed care settings. Ann Intern Med 1997;127(8 pt 2):719-24.

15 Cavalier S, Escobar GJ, Fernbach SA, et al. Postdischarge utilization of medical services by high-risk infants: experience in a large managed care organization. Pediatrics 1996;97:693-9.

16 Escobar GJ. The neonatal "sepsis work-up": personal reflections on the development of an evidence-based approach toward newborn infections in a managed care organization. Pediatrics 1999;103(1 suppl E):360-73.

17 Newman TB, Escobar GJ, Gonzales VM, et al. Frequency of neonatal bilirubin testing and hyperbilirubinemia in a large health maintenance organization. Pediatrics 1999;104(5 pt 2):1198-203.

18 Escobar GJ, Gonzales VM, Armstrong MA, et al. Rehospitalization for neonatal dehydration: a nested case-control study. Arch Pediatr Adolesc Med 2002; 156:155-61.

19 Meikle SF, Lyons E, Hulac $P$, et al. Rehospitalizations and outpatient contacts of mothers and neonates after hospital discharge after vaginal delivery. Am J Obstet Gynecol 1998;179:166-71.

20 Escobar GJ, Fischer A, Kremers R, et al. Rapid retrieval of neonatal outcomes data: the Kaiser Permanente Neonatal Minimum Data Set. Quality Management in Health Care 1997;5(4): 19-33.

21 Kramer MS, Demissie K, Yang H, et al. The contribution of mild and moderate preterm birth to infant mortality. Fetal and Infant Health Study Group of the Canadian Perinatal Surveillance System. JAMA 2000;284:843-9.

22 Holberg CJ, Wright AL, Martinez FD, et al. Risk factors for respiratory syncytial virus-associated lower respiratory illnesses in the first year of life. Am J Epidemiol 1991;133:1135-51.

23 Boyce TG, Mellen BG, Mitchel EF Jr, et al. Rates of hospitalization for respiratory syncytial virus infection among children in Medicaid. J Pediatr 2000;137:865-70

24 NIH Consensus Development Panel on the Effect of Corticosteroids for Fetal Maturation on Perinatal Outcomes. Effect of corticosteroids for fetal maturation on perinatal outcomes. JAMA 1995;273:413-18.

25 Richardson DK, Corcoran JD, Escobar GJ, et al. SNAP-\|l and SNAPPE-II: simplified newborn illness severity and mortality risk scores. J Pediatr $2001 ; 138: 92-100$

26 International Neonatal Network. The CRIB (clinical risk index for babies) score: a tool for assessing initial neonatal risk and comparing performance of neonatal intensive care units. The International Neonatal Network [published erratum appears in Lancet 1993;342:626], Lancet 1993;342:193-8

27 Newman TB, Xiong BX, Gonzales VM, et al. Prediction and prevention of extreme neonatal hyperbilirubinemia in a mature health maintenance organization. Arch Pediatr Adolesc Med 2000;154:1140-7.

28 Localio AR, Berlin JA, Ten Have TR, et al. Adjustments for center in multicenter studies: an overview. Ann Intern Med 2001;135:112-23.

29 Harrell FE Jr, Lee KL, Califf RM, et al. Regression modelling strategies for improved prognostic prediction. Stat Med 1984;3:143-52.

30 SAS. Statistical Analysis Software, 6th edn., Carey, NC: SAS Institute 1989.

31 Ventura SJ, Martin JA, Curtin SC, et al. Births: final data for 1999. Natl Vital Stat Rep $2001 ; 49(1): 1-100$.

32 Newman TB, Liljestrand P, Escobar GJ. Infants with total serum bilirubin levels $\geqslant 30 \mathrm{mg} / \mathrm{dl}$ in a large managed care organization. Pediatrics 2003;111:1303-11

33 Slater L. Home versus hospital phototherapy for term infants with hyperbilirubinemia: a comparative study. Pediatrics 1984;73:515-19.

34 Rogerson A. 14 Years of experience with home phototherapy. Clin Pediatr 1986;25:296-9.

35 Grabert B. Home phototherapy. An alternative to prolonged hospitalization of the full-term, well newborn. Clin Pediatr 1986;25:291-4.

36 Meropol SB, Luberti AA, De Jong AR, et al. Home phototherapy: use and attitudes among community pediatricians. Pediatrics 1993;91:97-100.

37 Poland RL. Home phototherapy: Not seeing the light. Pediatrics 1993;91:147.

38 Atkinson LR. Phototherapy use in jaundiced newborns in a large managed care organization: do clinicians adhere to the guideline? Pediatrics 2003;111:e555-61.

39 Plastino R. Impact of eligibility criteria on phototherapy program size and cost. Pediatrics 1990;85:796-800. 
40 Newman TB, Maisels MJ. Evaluation and treatment of jaundice in the term newborn: a kinder, gentler approach. Pediatrics 1992;89:809-18.

41 Spinner S. Earlier discharge of infants from neonatal intensive care units: a pilot program of specialized case management and home care. Clin Pediatr 1998;37:353-7.

42 Escobar GJ, Braveman PA, Ackerson L, et al. A randomized comparison of home and hospital-based group follow-up visits after early postpartum discharge. Pediatrics 2001;108:719-27.

43 Lieu TA, Braveman PA, Escobar GJ, et al. A randomized comparison of home and clinic follow-up visits after early postpartum hospital discharge. Pediatrics 2000; 105:1058-65
44 Green M, ed. Bright futures. Guidelines for health supervision of infants, children and adolescents. Arlington, VA: National Center for Education in Maternal and Child Health, 1994.

45 Escobar GJ, Fischer A, Li DK, et al. Score for neonatal acute physiology: validation in three Kaiser Permanente neonatal intensive care units. Pediatrics 1995;96(5 pt 1):918-22.

46 Kotagal UR, Atherton HD, Eshett R, et al. Safety of early discharge for Medicaid newborns. JAMA 1999;282:1150-6.

47 Phibbs CS, Bronstein JM, Buxton E, et al. The effects of patient volume and level of care at the hospital of birth on neonatal mortality. JAMA 1996;276:1054-9.

\section{ARCHIVIST}

\section{Allergy to insect stings: long term outcomes}

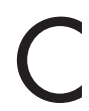

hildren get stung by insects and some of them (possibly around 1\%) have a systemic allergic reaction. Venom immunotherapy (VIT) reduces the risk of subsequent systemic reactions but its disadvantages include cost, inconvenience, local and systemic reactions, and the need for prolonged treatment. Researchers in Baltimore, USA have previously concluded that VIT is not necessary for children who have had a mild (purely cutaneous) systemic reaction to an insect sting. They have now reported (David BK Golden and colleagues New England Journal of Medicine 2004;351:668-74, see also editorial; ibid:707-9) on the long term follow up of children who did or did not receive VIT.

From a cohort of 1033 children who had a diagnosis of insect sting allergy made between 1978 and 1985, 512 responded to a survey between 1997 and 2002. Their mean age was 8 years at the time of their first reaction and 21 years at the time of the most recent reaction. Among children whose first systemic reaction was purely cutaneous, subsequent systemic reactions occurred after 12 of 89 stings (13\%) among children not given VIT and after none of 21 stings among children given VIT (difference not statistically significant). Of the 12 subsequent systemic reactions in the no-VIT group six were mild and six moderate in intensity. After a first moderate-to-severe reaction the corresponding rates of systemic reaction were 7/22 (32\%) without VIT and 2/43 (5\%) with VIT-a significant difference. Six of the seven subsequent reactions in the no-VIT group were similar to the first reaction and one was less severe; none was severe. Two patients had received VIT after a first severe reaction and had moderate reactions after subsequent stings.

Most children outgrow the allergy to insect stings but some (about 13\% of those not given VIT) still have a systemic allergic reaction when stung 20 years or more after the first reaction. The benefit of VIT seems to be long lasting, with significant protection 10-20 years after stopping the treatment (the mean duration of VIT among treated children in this study was 3.5 years).

Some children do not outgrow infant sting allergy. The authors of this paper recommend VIT for children who have had a moderate-to-severe systemic reaction (not purely cutaneous) after an insect sting. 